\title{
Mucous Membrane Topical Solution Dosage Form
}

National Cancer Institute

\section{Source}

National Cancer Institute. Mucous Membrane Topical Solution Dosage Form. NCI

Thesaurus. Code C91150.

A solution intended for administration to the surface of the mucosa membranes. 